\title{
Research on the Hybrid Teaching Pattern Reform Based on the Internet
}

\author{
Zezhou Zhong \\ Quanzhou Preschool Education College \\ Quanzhou, Fujian, 362000 \\ zzz851@126.com
}

\begin{abstract}
Along with the further development of education informatization, MOOC's appearance and thriving initiates a new climax of Internet Education. The connotation of Internetbased hybrid teaching pattern becomes more diversified. The modern vocational schools should keep pace with the development of the education reform by paying more attention and providing more supports in this process and conducting the hybrid education pattern reform in a scientific way. In the meanwhile, making use of the advantages of the online and traditional teaching by combining the online and off-online teaching pattern is also advisable. Schools should also adjust the education management way flexibly and providing students supports in different aspects to inspire students' initiation and positivity to join in the hybrid education pattern effectively. In this way, the study results of students and teaching quality will be improved and more modern talents with innovation ability will be cultivated.
\end{abstract}

Keywords-The Internet; Hybrid Teaching Pattern; Teaching reform; Teaching quality

\section{INTRODUCTION}

In 2013, the Ministry of Education mentioned the "Hybrid Teaching" in the introduction materials of excellent course construction. [1] In the October of 2014, Tsinghua University released Tsinghua University's several suggestions about overall deepening of Education Reform, where it mentioned the promotion the construction of MOOC, SPOC and hybrid courses and the application of new technologies in education depending on the online courses. The actions named "Desk Transformation" and "Platform flatten" accelerate the development of the online and offline hybrid teaching pattern, which can make students play the main roles in the process of teaching and studying. In hybrid classes, the interaction and communication of teachers and students will become more frequent, which can also inspire the initiation of students to take part in studying. In 2015, a piece of news of Tsinghua University named Redefining Classroom Begins from Desk Transformation and Flatten Platform became the one of the focuses of the public. In spring semester of 2015, Ocean University of China built a cooperation relationship with the education technology research institution of Tsinghua University to promote the hybrid teaching reform based modern information technology. 22 courses were taken into the hybrid teaching reform and conducted education activities with the new teaching pattern. (Chinese College and University, 2015) It was Professor Kekang He from Peking Normal
University who was the first one to advocate the concepts of hybrid teaching in China. From his view, the hybrid teaching pattern means the combination of the advantages of traditional teaching pattern and online teaching. It can not only take advantage of teachers' leading role for guidance, inspiration and monitor in the teaching process, but also make students play the main role for initiation, activation and creation in studying process. [2] From 2015, the number of papers concludes the key words "Hybrid Teaching" in titles has increased rapidly. Up to the June 20th in 2019, the number of papers with "Hybrid Teaching" in their titles is 2966. Until now, hybrid teaching has got broad attention and acceptance.

\section{INTERNET-BASED HYBRID TEACHING PATTERN REFORM IS IMPERATIVE}

Students who were born after 2000 live in the multimedia era and have various value orientations. Therefore, they have different ways to acquire knowledge from those generations before. The teaching pattern reform is a strategy to adapt to the college students in the new era by using some advanced teaching methods, which can inspire the initiation, inspiration and interests of students in study, changing students from passive place to the active place. The hybrid teaching pattern reform can drive teachers to change of teaching concept and enhance center-place of student in teaching. Also, it can promote the innovation of teaching methods and improve teaching ability. Certainly, the primary purpose of this kind of reversal teaching is to improve the teaching standard and quality further. According to Tianjin North website, students who took the experimental class of hybrid education reform in 2014 expressed that not only did they have more opportunities to express themselves in class; they also developed closer relationship with other students. In order to gain more chances to show themselves, students will search for more material related to the class, which will enlarge their reading quantities and knowledge scopes. Han Tian, one of those students, said "after studying online, we would bring personal questions and opinions to the 'knowledge bar' to refine knowledge by the brain storm with others. From my personal experience, this kind of teaching pattern can inspire my positivity in ideological class. In the meanwhile, it is also a way to improve our expressive and logical ability". He added that "as we usually choose a casual and quite place to conduct our group discussion, which makes us feel like talking in a bar. So, we call the places for group discussion as 'knowledge bar'”. Siyao Zuo, another student, introduced that "before the beginning of 
the class, we need to take the online class by ourselves taught by teachers who are famous in the related field. We call this kind of classes shared classes. When we study online, we can interact in the online community on the website and write down the confusions and difficulties. Classroom, café, library or dormitory all can be the places to study and the time for studying is flexible. For me, I prefer to take online classes in my dormitory”. A lot of students expressed that they took note in the class. After class, they needed to understand the knowledge and complete related assignments to consolidate the key points. As for those difficult problems, students can solve those problems by communicating with teachers or search on the Internet by themselves. This kind of study method can help students to cover the shortage of study and even study knowledge which is not included in the textbooks. Besides, the time of study is not limited; students can also login to the platform to study after class. Some students also said that with this double class pattern they learned a lot. Not only can they understand the knowledge better, they also improved the ability of analysis, find and solve problems independently. There were also some students asserted that they can study focus on their own confusions and shortages to improve the comprehensive and self-study ability. [3] With the fast development of micro lectures and MOOC relying on the information technology, "Internet+" combines with the higher education to exert great influence on the traditional classroom teaching pattern with hybrid teaching methods that feather with interests, equal and convenience. The teaching ways and patterns of higher education will experience a great change in the future. In June of 2016, the Ministry of Education released The Guidance about Deepen Education Reform in Colleges and Universities under Central Government, which asserted that the special project of colleges and universities under central government education teaching reform will be conducted during "the 13th five-year" plan to promote the combination of information technology and education teaching. In January of 2018, ministry of education released Work Focuses in 2018 for the Ministry of Education, which pointed out that China would start the 2.0 version of educational action plan to promote education informalization deeper. [4] At present, China is experiencing the key period of accelerating the transformation of development models and promoting the adjustment and upgrading of industry structure. In the meanwhile, along with the popularization of higher education, vocational colleges also need to break down the traditional concepts of the traditional higher education and vocational education to construct modern vocational education system positively to satisfy the needs of diversified talents during the development of regional economics and society, which is also an important task and strategy for vocational education. Under the circumstance of modern education, teaching is not just dependent on the lectures of teachers in class. If students want to acquire more knowledge to benefit their own development or satisfy their own interests, not only can they read the related knowledge in the textbooks. The new education informatization tide represented by The Flipped Classroom and MOOC provides larger study space, more diversified study materials and channels for students, which can in turn improve the self-study ability of students. For school, education informatization can improve the ability of Internet teaching ability of school.
Therefore, the hybrid teaching pattern reform based on the Internet is imperative.

\section{EXPLORING THE HYBRID TEACHING REFORM IN A SCIENTIFIC WAY--TAKE OUR SCHOOL AS AN EXAMPLE}

The self-study tide on the Internet can gather digital study materials, online class material and visual reality classes resources, which can combine vocational teaching and distance teaching concepts, online and offline study resource, traditional and digital teaching resources, the real practice and fictitious practices, the real circumstance study and visual reality (The Internet). It can greatly promote the hybrid teaching reform combining the face-to-face classroom education and digital education. The appearance and flourishing of MOOC lead to the new climax of Internet Education development. As an exemplary vocational school in our province, our school needs to start the hybrid education reform in a scientific way according to the real situation.

\section{A. Enhancing the standard of attention and provide more supports}

Considering the limitation of teaching resource, education fund, teaching facilities and etc., our school doesn't have enough ability to popularize the hybrid teaching pattern, which greatly restricts the improvement of teaching standard and quality. Whether a school pays attention to and supports the hybrid education reform can be a standard to testify whether a school puts teaching in the central place. Faced with the change of era, our school must have high cultural consciousness to explore the new connotations and paths in the teaching reform to improve the overall teaching quality.

\section{B. Schools should Conduct the Hybrid Education Reform in a Scientific Way}

In the teaching process construction based on the online teaching platform resources; teachers not only can exert the leading effects, but also become the main role in the process of inspiring students' studying initiation. [5] At present, the online class study is a way of self-study under the guidance of the class, studying and teaching theories. Considering the characters of normal schools, our school should take Constructivist Learning Theory as guidance and Action Research Method as method to development researches on teaching and studying based on information technologies. Combining the new course plans and course changing spirit, the information technologies will be integrated into the process of teaching and studying to promote the further development of education career and improve the students' ability of studying.

The promotion of hybrid teaching reform can't be conducted blindly or arbitrarily. It should be conducted according to the overall layout of school development in teaching. To choose suitable teaching methods and patterns, the different characters and demands of different institution, majors and courses should be taken into consideration. However, it is not necessary to conduct the hybrid teaching methods in every class. In some classes, the traditional teaching pattern will be more efficient compared with hybrid teaching methods. However, in some classes, the hybrid teaching 
methods will more helpful to complete teaching tasks and improve the teaching quality. Under this kind of condition, it is essential for school to have accurate assessment and perform scientific analysis before choosing teaching patterns. For example, from 2016, our school introduced the online class of MOOC and established the study and credit recognition institution based on the public basis courses. By analyzing the fiscal operation situation, it finds that students show great progress in study. School can also promote combination of classroom and online teaching among students with some online study platform by building high-quality course resources. In Tianjin University of Finance and Economic, the experimental course is Ideological and Moral Cultivation and Legal Basis for the construction of teaching reform. Based on the concept of conducting first and summarize experience first, this school gradually promoted the student-central hybrid education reform in the public basis course and major courses. The hybrid teaching pattern which placed students in the center place can gather students and teachers to explore a new flexible study way in the Cloud Era. Certainly. The teaching reform based on Internet circumstance can also adopt the way of taking place of parts of planned class hours and conducting the classes in a cross way of "teaching--self-studying+teaching-teaching”. For instance, the total class hours can be divided into the classroom teaching hours and the self-studying hours. Student can arrange some self-study hours online in the process of self-study. As the same time, students can combine the lecture teaching, knowledge and experience in practice to make study result as good as possible.

\section{Schools Transform the Teaching and Management Method Flexibly}

Online studying is the beneficial supplement of teaching in classroom; Hybrid teaching can be promoted in vocational colleges and improve its teaching quality; the results of Hybrid teaching depends on those teachers who are full of teaching experience and master modern education technologies. [6] In the Guidance Suggestions about the technologic talent cultivation and conduction work in vocational college, which was released on the 5th of June in 2019 by the Ministry of Education. In this document, it declared that the vocational college should promote the flipped classroom, hybrid teaching, combination of theories and practices and other new teaching pattern to promote the class teaching reform. [7] To improve the motivation of teachers to join into the reform of hybrid teaching, it is essential for schools to provide convenience and benefits to encourage them to join into the hybrid teaching reform. At present, the title evaluation, fiscal assessment, students' feedbacks and teaching research and other policies lead to the situation that teaching reform becomes the "conscious words" of teachers. Many teachers would rather read the textbook and power points than conduct the teaching reform. Let alone the hybrid teaching pattern which needs more energy. It is demonstrated that there are still some problems for school in the encouragement mechanism for teachers. School should enhance the training of modern information technologies and take the application ability of information technology into working evaluation for teachers; besides, schools should make some researches and design an institution of online class chosen and construction to encourage and support teachers to establish several high-quality courses. In this way, teachers will be inspired to join into the hybrid education reform.

\section{Providing Supports for Students to Join into the Hybrid Teaching Reform}

Students are the main groups of education. As all the activities of teaching are conducted around students, students become the main participants of hybrid teaching reform. School should provide supports for students in different aspects, inspiring the motivation and initiation of students to join into the hybrid teaching reform.

\section{1) Improving administration work of student}

The Hybrid Education Reform will decrease the class hours and increase the study hours after class for students, which influences the work of student management. For example, how to grasp the information of students' work and rest situation, how to monitor the study process of students and etc. Not only ought schools to enhance the daily administration of students, but also leave more flexible time and provide other convenience to students to arrange time to study online.

\section{2) Deepening Credit Institution Reform}

In order to promote the overall credit institution reform, there must be some related policies to be improved. The promotion of hybrid teaching reform should be combined with the credit institution reform. Some teachers hope to promote the hybrid teaching method and others do not. School can provide sufficient teaching resources and course recourses for students to choose with their own preference. Therefore, students can arrange their study with suitable paces.

\section{3) Improving the online teaching platform}

The number of classes on the online platform has increased fast along with the development information technology. The Internet platform about teaching includes the studying and teaching website, interaction and teaching management platforms. At presents, there are some platforms at home and abroad provide SPOC platform to help schools to conduct hybrid teaching. However, not all those platforms can satisfy the needs of school and students. Therefore, schools should accelerate the pace of information management platform construction and upgrade by introducing some high-quality courses and platforms and improving the management of informatization platform.

\section{4) Improve the Teaching Management System}

Though the teaching management system of our school has been upgraded, its functions still can't meet all the needs of students. Especially when our schools conduct the hybrid teaching pattern, the needs of choosing class and information inquiry will increase greatly.

5) Support the $S \& D$ of virtual simulation training system for class

Our school should make use of virtual three-dimensional international teaching platform to combine the traditional and digital teaching resource, physical and virtual training. It can improve the practical ability by realizing the practice training which can't be deducted with physical subjects. With the improvement of design, research and comprehension of study 
resources and the development teaching activities, our school can mix the technology education concepts and the distance education concepts, the online and offline study resources. Then our school can conduct a suitable online study pattern reform in some courses.

6) Strengthening the Construction of Hardware Facility such as The Internet

Schools are the provider of hardware. At present, our school should strengthen the construction of Internet facilities to provide Internet support for students to study online with the Internet terminal.

\section{CONCLUSION}

Certainly, the combination does not mean the mix of online and offline study patterns. It means breaking the isolation and solidification in the aspects of education model, education concepts, study objects and practical application. Hybrid teaching aims to build an open, character respective and more practical teaching pattern. Teaching reform is a way to explore the teaching methods and content by using the Internet and information resources. Based on the Internet circumstance, it can provide information with new designed and organized form; With the cross-conduction of self-study and teachers' lectures, it enhances the relationship of self-study and teaching processes. The communication between teachers and students can promote the right direction and effectiveness of self-study, which can also show the central place of students in education. For teaching, it's also a way to enrich the methods of teaching. By self-studying, students can improve their ability to find, analyzing and solving problems. In addition, the ability of Internet application and other core abilities for the future career of students will also be improved gradually.

To sum up, the hybrid teaching pattern, which seamlessly combines the teaching patterns of online and lectures will become a main trend in the future. [1] Every school should consider how to help students to study better online especially vocational colleges under the policies of teaching reform. In the further process of teaching reform, the school should combine the features of education informatization development to construct an effective mechanism, which can expand the coverage of the advanced education resources. In the meanwhile, schools should also accelerate the pace of online education platform construction and construction of MOOC in the era of the Internet + to promote the practical exploration of hybrid education pattern, which can be helpful for the results of teaching reform and cultivate the modern talents with outstanding innovation ability.

\section{REFERENCES}

[1] Chengxiu Yu. Research of hybrid education in technical college based on the Internet platform [J]. The senior teaching Journal.2019 (12) 89-95.

[2] Qiliang Zhang, Aichuan Wang. The research on the new Hybrid Teaching Pattern based on "Flipper Class". Modern Education Technologies. 2014, 4(24): 27-32.

[3] The Experiment of Hybrid Teaching Reform in Tianjin University of Finance and Economics. 2019, 6 (20) http://news.enorth.com.cn/system/2014/11/13/012261640.shtml

[4] The research Center of Ministry of Education for Online Education. The report of Chinese online open courses (2017) [M]. Beijing. Higher Education Press, 2018:3-4.

[5] Xiaolong Li, Chengrui Zhang, Bin Gen. Hybrid Teaching Pattern reform in Technical College: The Research and Enlightenment under MOOCs Era $[\mathrm{J}]$. Research on the Electronic and Chemistry education, 2015(12):52-58.

[6] Yue Lin, The practical Exploration on the application of Hybrid Teaching in technical College [J]. Education informatization in China, 2014(03):41-43.

[7] The Ministry of Education. The Guidance Suggestions about the technologic talents cultivation and conduction work in vocational college. [EB/OL].2019, 6(2)

http://www.moe.gov.cn/srcsite/A07/moe_953/201906/t20190618_38628 7.html 